\title{
Epidemiological Study of Hepatitis A in Plovdiv Region-Bulgaria, 2005-2008
}

\author{
Mariyana Stoycheva $^{*}$, Nikolay Vatev ${ }^{2}$, Andrey Petrov ${ }^{1}$, Chavdar Venchev ${ }^{1}$, Maria Atanasova ${ }^{3}$ \\ ${ }^{1}$ Department of Infectious Diseases, Parasitology and Tropical Medicine, Medical University Plovdiv, Plovdiv, Bulgaria; ${ }^{2}$ Department of \\ Hygiene, Ecology and Epidemiology, Medical University Plovdiv, Plovdiv, Bulgaria; ${ }^{3}$ Department of Microbiology, Immunology \\ and Virology, Medical University Plovdiv, Plovdiv, Bulgaria. \\ Email: $\left\{{ }^{*}\right.$ mariana_stoycheva, dr_andre_petrov,dr_venchev, atanmim $\} @$ yahoo.com, nikolay_vatev@abv.bg
}

Received July $12^{\text {th }}, 2011$; revised August $25^{\text {th }}, 2011$; accepted September $4^{\text {th }}, 2011$.

\begin{abstract}
Background: Hepatitis A is a social disease and has great importance for public health in countries with high level of incidence rate. The problem is particularly serious for Bulgaria because the morbidity rate in the country is several times higher in comparison with the other countries of the European Union. The aim of the study is to establish the contemporary epidemiological characteristics of viral hepatitis A in Bulgaria. Methods: Analysis of the incidence rate and the age distribution has been done among two groups of the population differentiated depending on their hygienic living conditions: $1^{\text {st }}$ group —living in bad hygienic conditions; $2^{\text {nd }}$ group -living in good hygienic conditions. A large epidemic outbreak of hepatitis A with 1004 persons of Roma origin has been described. The comprehensive method for epidemiological research and serological methods for determining the diagnosis have been used. To study the risk factors the methods of case-control and multi-factor logistic regression are used. Results: Nine times higher incidence rate has been established in the $1^{\text {st }}$ group 450/100,000 in comparison with the $2^{\text {nd }} 50 / 100,000$. The patients from the $1^{\text {st }}$ group are predominantly children aged 5 - 9 years and from the $2^{\text {nd }}$ adults aged $30-39$ years. The level of significance of the risk factors for the biggest epidemic outbreak has been established-bad personal hygiene is of the greatest importance. The risk for travellers to countries and regions with high endemicity and during epidemic outbreaks has been shown. Conclusions: There are essential differences in the epidemiology of HAV between the groups with different hygienic living conditions. That is why the analyses of the incidence rate and age distribution of hepatitis $A$ have to be done separately for different population groups. Recommendations for providing differentiated measures for prevention and control of hepatitis A among the two groups are given.
\end{abstract}

Keywords: Hepatitis A, Incidence Rate, Epidemic Outbreak, Risk Factors

\section{Background}

Hepatitis A has been known to health practice for many years, although modern serological methods for diagnosis, methods of molecular epidemiology and licensed vaccines are more recent. HAV is widespread worldwide, but its frequency is various in different countries. Indices of the endemicity for a particular country are the seroprevalence level of the population and the incidence rate. According to the latest classification of the Centers for Disease Control and Prevention the world is divided into four zones with different endemicity: 1. High; 2 . Transitional; 3. Intermediate; 4. Low to very low [1]. The term HAV has been introduced for the first time by Krugman et al. in 1967 [2]. Epidemiologic and transmission studies with humans showed that hepatitis A is transmitted primarily via faecal-oral route [3-5]. Contemporary knowledge of HA virus infection dates since 1973 when hepatitis A virus (HAV) was identified in the stools of infected persons [6]. About 20 years later the methods of molecular epidemiology are already used as well [7-9] to test the epidemiology of HAV. Meanwhile the elaborated killed vaccines against the disease are licensed and put into practice. They possess very good qualities and result in the formation of antibodies for almost all immunized [10-13].

Despite the considerable lowering in the incidence rate of HAV in some countries due to improved sanitaryhygienic conditions and the use of the vaccine, no country so far has announced the eradication of the problem with the disease $[14,15]$. HAV is a social disease and has great importance for public health. We mean that mor- 
bidity (at least in Bulgaria) of HAV is still high and for many people it results in disability for 1 - 2 months and significant financial resources are spent to treat patients. The problem is especially serious because the morbidity rate in our country is several times higher than in other countries of the European Union. Permanent surveillance of the disease is necessary. This is due to the fact that HAV represents risk to a lot of travellers [16-18]. Therefore, the medical practice needs knowing the epidemiology of HAV not only in its own country but in other countries around the world as well.

Aims of the study: 1) To establish the contemporary epidemiological characteristics of viral hepatitis A in Plovdiv region, Bulgaria. 2) To determine the importance of the different risk factors for the high incidence of HAV. 3) To recommend more effective measures for prevention and control of the disease.

\section{Methods}

A total of 3911 patients with HAV who were treated in the Clinics of Infectious diseases, Medical UniversityPlovdiv, during the period 2005-2008 were included in the study. The diagnosis of all patients was confirmed by positive anti-HAV IgM test. ELISA method was used with kits and apparatuses of Dia Sorin. The immunoassays were performed in the Department of Microbiology, Immunology and Virology, Medical University-Plovdiv. Methods of clinical and laboratory analyses were used with appropriate biochemical and ultrasound tests. The comprehensive method for epidemiological research and analysis has been used.

Plovdiv region is located in the middle of South Bulgaria. It is the second biggest region in the country and covers $1 / 10$ of its territory with about 410,000 inhabitants of all 7.6 millions for Bulgaria.

The incidence rate and the age distribution have been examined and compared in two separate groups of the population according to their hygienic living conditions: $1^{\text {st }}$ group-living in bad sanitary-hygienic conditions (most from Roma origin); $2^{\text {nd }}$ group-living in good hygienic conditions. The incidence rate is calculated as $\mathrm{N}$ of cases/100,000 inhabitants for the whole population or for the respective group of the population.

We define the hygienic conditions of life as bad when a person lives in an overpopulated neighborhood with frequent break-downs in the water supply and the sewage systems, irregular electricity supply, bad organization of garbage collection. In addition in the houses there are no separate kitchens with running water (several families use only one sink which in many instances is located in the yard); there is no bathroom and toilet with running water; housing area is not cleaned regularly; the person has poor hygiene habits - does not regularly wash hands before meals and after using the toilet; the housing area is overpopulated - in many of the cases 4 to 5 family members live in 1 room. When the conditions are opposite to those described, we have defined them as good.

\section{Statistical Analyses}

Processing, analysis and graphic representation of the data and the results have been performed on a PC using routine statistical programs (MS Excel, SPSS ver. 11).

The method of case-control study has been used to determine the degree of the risk factors for the described outbreak of HAV. It was based on 307 patients of HAV (part of the patients from the $1^{\text {st }}$ group only) and 413 healthy persons who were in close contact with them and who also lived in bad hygienic conditions. The cases and the controls were aged up to 9 years.

We studied 6 risk factors (RF) for hepatitis A: RF1bad hygienic habits; RF2-overpopulated household; RF3 - break-downs in the water supply; RF4 - irregular electricity supply; RF5-low financial status; RF6intensive migration. We determine the mean of the different risk factors as follows:

Bad personal hygiene-we mean not washing hands before meals.

Overpopulated household - for the standardization of this indicator, we used an indirect method, whereby the indicator in the standard population is compared with that of the studied population. For this purpose we studied 220 patients who do not live in gipsy neighbourhoods. In this population we found an average living area per family member $18.34 \mathrm{~m}^{2}$, ranging from 14.82 to $27.53 \mathrm{~m}^{2}$. For overpopulated housing we have assumed an indicator in which the area for each family member is below $10 \mathrm{~m}^{2}$.

Low financial status - income per family member below the minimum living standard for the country according to the Ministry of Labour and Social Affairs of Bulgaria. In many cases these are people with monthly income of 50 - 70 bulgarian levs, equal to 30 - 45 USD.

Intensive migration - those are cases in which a family member/members visit their relatives (or receive such visits), travel to other places to look for work at least once within the maximum incubation period of the disease (50 days).

Break-downs in the water supply-daily interruption of water supply for more than 4 hours. In many of the cases and the controls there was water supply between 00:00 and 05:00 o'clock.

After data analysis of the case-control study a statistical analysis was carried out of the combined effect of the six risk factors which have a dichotomous codeRF1 $(0=$ absent, $1=$ present $), \operatorname{RF} 2(0=$ absent, $1=$ pre- 
sent), RF3 ( 0 = absent, 1 = present $), \operatorname{RF} 4(0=$ absent, $1=$ present $)$ RF5 $(0=$ absent, $1=$ present $), \operatorname{RF} 6(0=$ absent, $1=$ present). Multiple step logistic regression analysis was applied.

The data for all analyses were collected after informed consent of all participants was obtained. We obtained an approval from the ethics committee of the Medical University-Plovdiv.

\section{Results and Discussion}

\subsection{Incidence Rate of HAV (2005-2008) for the Whole Population in the Region}

During the period of the study the incidence rate varied widely (Table 1). It is respectively: 2005-52.74/100,000; 2006-426/100,000; 2007-69.4/100,000, 2008-4.25/ 100,000 . The sharp increase of the incidence rate in 2006 is due to the large epidemic outbreak of HAV in Plovdiv region. The data from the outbreak were examined separately. The incidence rate is the highest in the age group 5 - 9 years, followed by the group $1-4$ years. The patients aged $1-9$ years represent $51.3 \%$ of all clinical cases for the period. Regarding the older age groups morbidity decreases as age increases and has its lowest rate for those aged over 60 years.

Reported asymptomatic cases in children up to 9 years are $197(15.06 \%)$. But the figures do not meet the actual number, since in routine practice in Bulgaria not all contact persons are being tested for anti-HAV IgM. We conducted another study to establish the incidence of asymptomatic forms of HAV infection. In the source of infection in the contacts of diseased children from group 1 aged up to 9 years we have found asymptomatic forms in $58 \%$ of the tested patients. For children under 9 years from group 2 they were $41 \%$ (unpublished data).

\subsection{Incidence Rate and Age Distribution in the Two Groups $\left(1^{\text {st }}\right.$ and $\left.2^{\text {nd }}\right)$ Living in Different Sanitary-Hygienic Conditions}

There is a very strict registration and announcement of the infectious diseases in Bulgaria (Bulgarian Ministry of Health, Instruction for Prevention and Control of viral hepatitis in Bulgaria, 1995, Sofia, 1 - 4). In accordance with the requirements of the Ministry of Health every infectious disease, including HAV, has to be registered and announced to the Regional Inspection for Prevention and Control of Public Health. But the registration is for the whole population of the region, respectively for the country. During the examination we observed that most of the cases come from bad sanitary-hygienic conditions. They were predominantly of Roma origin, who live in densely populated areas, where most of them do not have essential hygienic habits (washing hands). For that reason we divided all HAV diseased in 2 groups according to the main risk factor for the high morbidity of HAV (hygienic conditions of life): $1^{\text {st }}$ group - living in bad hygienic conditions; $2^{\text {nd }}$ group-living in good hygienic conditions.

For the examined period the incidence rate in the $1^{\text {st }}$ group is 9 times higher than the incidence of the $2^{\text {nd }}$ group -450.66/100,000 and 50.26/100,000 respectively (Table 2).

Improvement in the sanitary-hygienic conditions results in a considerable decrease of the incidence rate of HAV. However, this improvement does not comprise all groups of the population in a particular region or country. Therefore it is necessary to conduct differentiated moni-

Table 1. Incidence rate $(100,000)$ according to years and age for the whole population.

\begin{tabular}{|c|c|c|c|c|c|c|c|c|c|c|}
\hline \multirow{2}{*}{$\begin{array}{c}\text { Year } \\
\text { Age }\end{array}$} & \multicolumn{2}{|c|}{2005} & \multicolumn{2}{|c|}{2006} & \multicolumn{2}{|c|}{2007} & \multicolumn{2}{|c|}{2008} & \multirow{2}{*}{$\begin{array}{l}\text { Total } \\
\text { Cases }\end{array}$} & \multirow{2}{*}{$\begin{array}{l}\text { Average } \\
\text { Inc. rate }\end{array}$} \\
\hline & Cases & Inc. rate & Cases & Inc. rate & Cases & Inc. rate & Cases & Inc. rate & & \\
\hline 0 - 4 & 34 & 189.19 & 699 & 2970.81 & 49 & 210.97 & 5 & 19.6 & 787 & 847.64 \\
\hline $5-9$ & 90 & 398.5 & 1048 & 3679.65 & 83 & 291.42 & 2 & 6.76 & 1223 & 1094.08 \\
\hline $10-14$ & 78 & 151.83 & 385 & 1140.77 & 58 & 171.86 & 0 & 0 & 521 & 366.12 \\
\hline $15-19$ & 36 & 75.65 & 212 & 459.27 & 63 & 136.48 & 4 & 9.43 & 315 & 170.21 \\
\hline $20-29$ & 49 & 44.5 & 279 & 357.36 & 91 & 84.08 & 6 & 5.49 & 425 & 99.23 \\
\hline 30 - 39 & 42 & 43.08 & 184 & 182.3 & 66 & 64.84 & 4 & 3.73 & 296 & 74.76 \\
\hline $40-49$ & 29 & 29.01 & 156 & 158.25 & 48 & 48.9 & 6 & 6.19 & 239 & 60.54 \\
\hline 50 - 59 & 15 & 15.48 & 47 & 48.26 & 26 & 26.78 & 2 & 2.08 & 90 & 15.65 \\
\hline$>60$ & 2 & 1.86 & 4 & 3.28 & 8 & 5.8 & 1 & 0.97 & 15 & 2.98 \\
\hline Total & 375 & 52.74 & 3014 & 426 & 492 & 69.4 & 30 & 4.25 & 3911 & 138.01 \\
\hline
\end{tabular}


Table 2. Incidence rate $(\mathbf{1 0 0 , 0 0 0 )}$ of $\mathrm{HAV}$ in the two groups.

\begin{tabular}{lcccccc}
\hline \multicolumn{1}{r}{ Year } & & $\mathbf{2 0 0 5}$ & $\mathbf{2 0 0 6}$ & $\mathbf{2 0 0 7}$ & $\mathbf{2 0 0 8}$ & $\mathbf{2 0 0 5 - 2 0 0 8}$ \\
\hline \multirow{2}{*}{$\mathbf{1}^{\text {st }}$ group } & cases & 67 & 1164 & 21 & 7 & 1259 \\
& inc. rate & 95.85 & 1665.3 & 30.04 & 10.01 & 450.66 \\
\multirow{2}{*}{$\mathbf{2}^{\text {nd }}$ group } & cases & 31 & 417 & 87 & 11 & 546 \\
& inc. rate & 11.46 & 153.34 & 32.03 & 3.99 & 50.26 \\
\hline
\end{tabular}

toring for control and prevention of the disease for the separate groups of the population, depending on whether the groups are at risk or not.

The analysis of the age distribution (Table 3) shows that most of the cases in the $1^{\text {st }}$ group $(41.62 \%)$ are from the age group 5 - 9 years. And the highest number of the patients from the $2^{\text {nd }}$ one $(21.89 \%)$ are aged 30 - 39 years.

In another study between 05.01.2008 and 28.03.2008 we established that the seroprevalence of HAV among individuals aged $16-43$ years from the $1^{\text {st }}$ group is above $90 \%$ and among individuals in the same age from the $2^{\text {nd }}$ group is below $45 \%$ [19].

We identified considerable differences in the epidemiology (incidence rate, age distribution, seroprevalence of anti-HAV $\mathrm{t}$ ) of $\mathrm{HAV}$ among individuals living in different sanitary-hygienic conditions.

Reduction of the incidence rate and seroprevalence among those living in good sanitary-hygienic conditions increases the risk of becoming infected and diseased for adults. Therefore, for them it is appropriate to conduct immune prevention (in contrast to the adults in the other group) if they are in contact with HAV infected, or if they are travelling to a country endemic for the disease. This is a new recommendation, additional to the measures for prevention of the disease, which have thus far been supplied for the population of the country as a whole.

\subsection{Registered Epidemic Outbreaks of HAV from 2005-2007}

In different countries different definitions for outbreak are used. Bulgaria has adopted the definition according to which the occurrence of three or more cases with an epidemiological link between them is considered as an outbreak.

During the study period we found 62 epidemic outbreaks with 2276 patients - $58.64 \%$ of all the cases (Table 4). In 2005-13 epidemic outbreaks arose with 166 diseased. The continuance of the separate outbreaks is from 30 to 150 days. It shows the length of the shortest and longest outbreak. In 2006 the epidemic outbreaks were 44, with 2048 diseased (67.94\% of all cases for the year). The continuance of the different outbreaks is from
20 to 250 days. During one of the outbreaks 5 people were diseased for a period of 20 days, and during another 20 people were diseased for a period of 50 days. In 2007 only 5 outbreaks are registered, with 62 diseased (12.6\% from all for the year). In 2008 there weren't any Registered outbreak.

The largest outbreak in 2006 was this in the Stolipinovo quarter, with 40,000 inhabitants mainly of Roma origin. The hygienic conditions of life in the neighbourhood are bad. During the outbreak (from the end of June until December 2006) 1004 people got diseased of HAV -incidence rate 2510/100,000. According to age the cases are distributed as follows: 0 - 1: $5 ; 1$ - 4: 305; 5 - 9: 437; 10 - 14: 96; 15 - 19: 45; 20 - 24: 41; 25 - 29: 35; 30 - 34: 14; 35 - 39: 8; 40 - 44:9; 45 - 49: 7; 50 - 54: 1; over 60: 1 . The incidence rate of HAV in the neighbourhood is higher compared to the rest, but under non-epidemic circumstances only sporadic cases or several cases in the same centre of infection occur, as the disease is transmitted predominantly by person-to-person contact. During the epidemiological examination at the time of the outbreak we observed serious break-downs in the sewerage system, the water-supply was irregular, and sometimes the drinking water was macroscopically contaminated. Microbiologic study confirmed its faecal contamination (E. coli was isolated) and it was recommended to the inhabitants to drink bottled water. However, some people disregarded the recommendation or did not have the finances to comply with it. Based on the findings of the study we suppose that the water mechanism was also participating in the transmission of the disease during the outbreak. Due to the increasing number of patients in August and September the Ministry of Health came to the decision that the population aged $1-18$ years in the neighbourhood, as well as in other neighbourhoods in Plovdiv with predominantly Roma inhabitants has to be immunized. The vaccine (Havrix) was applied by the end of October and about 30 days later-04.12.2006, the last HAV case in Stolipinovo was reported.

We wish to emphasize that by examining the differences in the incidence rate and the seroprevalence between the Roma and the rest of the population we do not consider the issue to be of ethnic nature. The differences 
Table 3. Age distribution of the patients with HAV in the two groups.

\begin{tabular}{|c|c|c|c|c|c|c|c|c|c|}
\hline \multirow{2}{*}{ age } & \multicolumn{3}{|c|}{$1^{\text {st }}$ group } & \multicolumn{3}{|c|}{$2^{\text {nd }}$ group } & \multicolumn{3}{|c|}{ Total } \\
\hline & cases & $\%$ & $\mathrm{Sp}$ & cases & $\%$ & $\mathrm{Sp}$ & cases & $\%$ & $\mathrm{Sp}$ \\
\hline $0-4$ & 693 & 26.01 & 0.81 & 94 & 7.54 & 0.74 & 787 & 20.12 & 0.61 \\
\hline $5-9$ & 1109 & 41.62 & 0.98 & 114 & 9.14 & 0.83 & 1223 & 31.27 & 0.73 \\
\hline $10-14$ & 427 & 16.03 & 0.71 & 94 & 7.54 & 0.74 & 521 & 13.32 & 0.54 \\
\hline $15-19$ & 216 & 8.11 & 0.56 & 99 & 7.94 & 0.75 & 315 & 8.05 & 0.43 \\
\hline $20-29$ & 162 & 6.08 & 0.44 & 263 & 21.09 & 1.09 & 425 & 10.87 & 0.49 \\
\hline $30-39$ & 23 & 0.86 & 0.17 & 273 & 21.89 & 1.11 & 296 & 7.57 & 0.42 \\
\hline $40-49$ & 15 & 0.56 & 0.15 & 224 & 17.96 & 1.02 & 293 & 6.11 & 0.40 \\
\hline $50-59$ & 18 & 0.67 & 0.16 & 72 & 5.77 & 0.65 & 90 & 2.30 & 0.25 \\
\hline$>60$ & 1 & 0.04 & 0.04 & 14 & 1.12 & 0.29 & 15 & 0.38 & 0.09 \\
\hline Total & 2664 & 100.00 & - & 1247 & 100.00 & - & 3911 & 100.00 & - \\
\hline
\end{tabular}

Table 4. Epidemic outbreaks.

\begin{tabular}{ccccc}
\hline Year & No. of outbreaks & No. of cases in all outbreaks & Average No. of cases in $\mathbf{1}$ outbreak & Continuance of the outbreak \\
\hline $\mathbf{2 0 0 5}$ & 13 & 166 & 12.77 & $30-150 \mathrm{~d}$ \\
$\mathbf{2 0 0 6}$ & 44 & 2048 & 46.54 & $20-250 \mathrm{~d}$ \\
$\mathbf{2 0 0 7}$ & 5 & 62 & 12.4 & $90-180 \mathrm{~d}$ \\
\hline
\end{tabular}

are due to the dissimilar sanitary-hygienic conditions of life.

As a result of vaccinating aforementioned population in Plovdiv a radical change occurred with regard to relative part of the HAV diseased in both groups. In 2007 the diseased in the 2nd group in Plovdiv were $87.1 \%$ of all clinical cases. In other towns and villages (i.e., inhabited areas) of the Plovdiv region such a change did not occur, and the status quo was retained, where about $70 \%$ of all cases arise among the population in the 1st group. That's why the incidence rate for the whole population of Plovdiv region for 2007 in the $1^{\text {st }}$ group is $30.04 / 100,000$ and in the $2^{\text {nd }}-32.03 / 100,000$.

The analysis of the data from the case-control study established the following results for the risk factors: RF1 -bad hygienic habits: OR $-3.19 ; 95 \% \mathrm{CI}-2.15 \div 4.74$; $P<0.001$; RF2 - overpopulated household (OR-2.81; $95 \% \mathrm{CI}-1.85 \div 4.27 ; P<0,001)$; RF3 - break-downs in the water supply $(\mathrm{OR}-1.50 ; 95 \% \mathrm{CI}-1.07 \div 2.10 ; P<$ $0.05)$ and RF6 - intensive migration (OR-1.89; 95\% CI $-1.40 \div 2.56 ; P<0.001)$. The irregular electricity supply (RF4) is not associated with the disease (OR-1.23; $95 \% \mathrm{CI}-0.76 \div 1.97 ; P>0.05)$ and the association for the low financial status (RF5) is debatable (OR-2.22; $95 \% \mathrm{CI}-1.03 \div 4.82 ; P=0.05)$.
The results from the logistic regression analysis are demonstrated in Table 5.

The best statistical multifactor model of disease progression depending on risk factors can be described using the following function:

$$
P=1 /[1-\exp (-X)]
$$

where $P$ is the probability the patient to develop HAV, and $X=-3.79+1.64 * \mathrm{RF} 1+1.34 * \mathrm{RF} 2+1.10 * \mathrm{RF} 3$ $+0.58 * \mathrm{RF} 6$. The reliability of the logistic regression model is very high $\left(r^{2}=0.19, \chi^{2}=112.34, P<0.0001\right)$.

The logistic regression analysis revealed the greatest importance of RF1 - bad hygienic habits with coefficient of regression 1.64. Next important are RF2, RF3 and RF6 with coefficients of regression respectively: 1.34; 1.10 and 0.58 .

During the examination we detected several patients as travellers in the region during that time, or students in some of the universities in Plovdiv from other countries, who became infected in Plovdiv, where later after going back to their home countries, they infected other members of their families or their acquaintances, with whom they were in contact. Unfortunately, we do not have information for all these cases, since they are not reported separately. During the epidemic outbreak the incidence 
Table 5. Results of the logistic regression analysis of the risk factors.

\begin{tabular}{|c|c|c|c|c|c|c|}
\hline Risk factor & B & S.E. & $P$ & $\operatorname{Exp}(B)$ & \multicolumn{2}{|c|}{ 95\% C.I. for EXP (B) } \\
\hline $\mathrm{RF} 1(1)$ & 1.64 & 0.22 & $<0.001$ & 5.13 & 3.32 & 7.94 \\
\hline $\mathrm{RF} 2(1)$ & 1.34 & 0.23 & $<0.001$ & 3.82 & 2.42 & 6.03 \\
\hline RF3(1) & 1.10 & 0.20 & $<0.001$ & 2.99 & 2.04 & 4.41 \\
\hline RF6(1) & 0.58 & 0.17 & $<0.001$ & 1.79 & 1.29 & 2.47 \\
\hline Constant & -3.79 & 0.39 & $<0.001$ & 0.02 & & \\
\hline
\end{tabular}

rate of HAV increased with regard of all groups of the population. This increased risk of infection affects not only the local population but also the travellers in the region.

\section{Conclusions}

1) The results of the study show essential differences between the groups of different hygienic living conditions. To establish the real risk of hepatitis A for the population it is necessary differentiated analysis of the morbidity, the age distribution and the seroprevalence among persons, living in different hygienic conditions.

2) The measures for prevention and control of HAV have to be different depending on the epidemiologic characteristics of the disease for the group of the population, to which the persons belong. At present in the routine medical practice in Bulgaria the measures for prevention are the same for the whole population.

3 ) It is necessary to send current information for every new epidemic outbreak of infectious diseases (including HAV) in different countries or country regions to Euro Surveillance (EWRS). Thus unbiased estimations will be feasible with regard to the presence as of respective moment of risk for a particular disease (or the absence of such), and also satisfactory recommendations on the prevention of travellers when they leave for a certain country or region will be viable. The described outbreak of HAV with 1004 patients arose in the end of June 2006 and was announced to Euro Surveillance at the end of September 2006 [20].

4) The study of the risk factors in simultaneous action (logistic regression) determines the degree of importance of each of them as follows: a) bad hygienic habits. b) overpopulated household. c) break-down in the water supply. d) intensive migration. The measures for prevention have to be linked to the elimination of these factors or when travelling to provide the necessary immune prophylaxis.

\section{Competing Interests}

There are not financial or other competing interests.

\section{Authors' Contributions}

Nikolay Vatev-conceived of the study, participated in its design and coordination and performed the statistical analyses.

Mariyana Stoycheva - participated in the design and coordination of the study, helped to scdraft the manuript.

Andrey Petrov-participated in the sequence alignment.

Chavdar Venchev—-participated in the sequence alignment.

Maria Atanasova - carried out the immunoassays.

\section{Acknowledgements}

We acknowledge Monika Troyancheva, MD, Director of Direction Prevention and Control of Infectious Diseases -Regional Inspection for Prevention and Control of Public Health (Plovdiv) for some data, which were necessary to evaluate the incidence rate of HAV in Plovdiv region.

We acknowledge Rumen Stefanov, MD, Ph D, Head of the Dept. Social Medicine-Medical University (Plovdiv) for the help to perform the statistical analysis.

We acknowledge also the Medical University-Plovdiv which bought the kits for the immunoassays.

\section{REFERENCES}

[1] K. H. Jacobsen and J. S. Koopman, "Declining Hepatitis A Seroprevalence: A Global Review and Analysis," Epidemiology and Infection, Vol. 132, No. 6, 2004, pp. 1005-1022. doi:10.1017/S0950268804002857

[2] S. Krugman, J. P. Giles and J. Hammond, "Infectious Hepatitis. Evidence for Two Distinctive Clinical, Epidemiological and Immunological Types of Infection," Journal of the American Medical Association, Vol. 200, No. 5, 1967, pp. 365-373. doi:10.1001/jama.200.5.365

[3] S. J. Staes, T. L. Schlenker, I. Risk, K.G. Cannon, H. Haris and A. T. Pavia, "Sources of Infection among Persons with Acute Hepatitis A and No Identified Risk Factors during a Sustained Community-Wide Outbreaks," Pediatrics, Vol. 106, No. 4, 2000, p. E54. doi:10.1542/peds.106.4.e54 
[4] P. Mathur and N. K. Arora, "Epidemiological Transition of Hepatitis A in India: Issues for Vaccination in Developing Countries," Indian Journal of Medical Research, Vol. 128, No. 6, 2008, pp. 699-704.

[5] G. De Serres, T. I. Cromeans, B. Levesque, M. Brassard, C. Barthe, M. Dionne, H. Prudhomme, D. Paradis, C. N. Shapiro, O. V. Nainan and H. S. Margolis, "Molecular Confirmation of Hepatitis A Virus from Well Water, Epidemiology and Public Health Implications," Journal of Infectious Diseases, Vol. 179, No. 1, 1999, pp. 37-43. doi:10.1086/314565

[6] S. M. Feinstone, A. Z. Kapikan and R. H. Purcell, "Hepatitis A: Detection by Immune Electron Microscopy of a Virus-Like Antigen Associated with Acute Illness," Science, Vol. 182, No. 116, 1973, pp. 1026-1028. doi:10.1126/science.182.4116.1026

[7] B. B. Goswami, W. Burkhardt and T. A. Cebula, "Identification of Genetic Variants of Hepatitis A Virus," Journal of Virological Methods, Vol. 65, No. 1, 1997, pp. 95103. doi:10.1016/S0166-0934(97)02179-4

[8] T. I. Cromeans, O. V. Nainan and H. S. Margolis, "Detection of Hepatitis A Virus RNA in Oyster Meat," $A p$ plied and Environmental Microbiology, Vol. 63, No. 6, 1997, pp. 2460-2463.

[9] J. Jean, B. Blais, A. Darvean and I. Fliss, "Detection of Hepatitis A Virus by Nucleic Acid Sequence-Based Amplification Technique and Comparison with Reverse Transcription-PCR," Applied and Environmental Microbiology, Vol. 67, No. 12, 2001, pp. 5593-5600. doi:10.1128/AEM.67.12.5593-5600.2001

[10] B. P. Bell, "Global epidemiology of hepatitis A: implications for control strategies," In: H. S. Margolis, M. J. Alter, J. T. Liand and J. I. Dienstag, Eds., Viral Hepatitis and Liver Disease, International Medical Press, London, 2005, pp. 9-14,.

[11] S. R. Bialek, D. A. Thoroughman, D. Hu, E. P. Simard, J. Chattin, J. Cheek and B. P. Bell, "Hepatitis A Incidence and Hepatitis A Vaccination among American Indians and Alaska Natives 1990-2001," American Journal of Public Health, Vol. 94, No. 6, 2004, pp. 996-1001. doi:10.2105/AJPH.94.6.996

[12] A. E. Fiore, A. Wasley and B. P. Bell, "Prevention of Hepatitis A through Active or Passive Immunization: Recom- mendations of the Advisory Committee on Immunization Practice (ACIP)," MMWR Recommendations and Reports, Vol. 55, No. RR-7, 2006, pp. 1-23.

[13] N. S. Crowcroft, B. Walsh and K. L. Davison, "Gundabissoon $U$ on Behalf of PHLS Advisory Committee on Vaccination and Immunization, Guidelines for the Control of Hepatitis A Virus Infection," Communicable Disease and Public Health, Vol. 4, No. 3, 2001, pp. 213-227.

[14] C. T. Leach, "Hepatitis A in the United States," Pediatric Infectious Disease Journal, Vol. 23, No. 6, 2004, pp. 551553. doi:10.1097/01.inf.0000130071.03003.c2

[15] B. Pham, B. Duval, G. De Serres, V. Gilca, A. C. Tricco, J. Ochnio and D. W. Scheifele, "Seroprevalence of Hepatitis A, Infection in a Low Endemicity Country: A Systematic Review," BMC Infectious Diseases, Vol. 5, 2005, p. 56. doi:10.1186/1471-2334-5-56

[16] K. Van Herck, P. Van Damme, F. Castelli, J. Zuckerman, H. Nothdurft, A. L. Dahlgren, S. Gisler, R. Steffen, P. Gargalianos, R. Lopéz-Vélez, D. Overbosch, E. Caumes, E. Walker, "Knowledge, Attitudes and Practices in TravelRelated Infectious Diseases: The European Airport Survey," Journal of Travel Medicine, Vol. 11, No. 1, 2004, pp. 3-8. doi:10.2310/7060.2004.13609

[17] H. D. Nothdurft, A. La Dahlgren, E. A. Gallagher, H. Kollaritsch, D. Overbosch, M. L. Rummukainen, P. Rendi-Wagner, R. Steffen and P. Van Damme, "The Risk of Acquiring Hepatitis A and B among Travelers in Selected Eastern and Southern Europe and Non-European Mediterranean Countries: Review and Consensus Statement on Hepatitis A and B Vaccination," Journal of Travel Medicine, Vol. 14, No. 3, 2007, pp. 181-187. doi:10.1111/j.1708-8305.2007.00123.x

[18] B. Genton, V. D’Acremont, H. J. Furrer, C. Hatz and L. Loutan, "Hepatitis A Vaccines and the Elderly," Travel Medicine and Infectious Disease, Vol. 4, No. 6, 2006, pp. 303-312. doi:10.1016/j.tmaid.2005.10.002

[19] N. Vatev, M. Atanasova, J. Stoilova, T. Chervenyakova and M. Troyancheva, "Seroprevalence of Hepatitis A Viral Infection in Plovdiv, Bulgaria," Folia Medica, Vol. 1, 2009, pp. 70-73.

[20] M. Kojouharova and Editorial Team, "Current Outbreak of Hepatitis A in Bulgaria, 2006," European Surveillance, Vol. 11, No. 40, 2006, pp. 30-49. 